\title{
Assimetria tensional nos membros superiors
}

Blood pressure difference between arms

Apresenta-se o caso de uma mulher de 69 anos, com antecedentes de Hipertensão arterial, Dislipidémia e Patologia degenerativa osteoarticular, referenciada à Consulta Externa de Medicina Interna por assimetria nos valores tensionais dos membros superiores conhecida há 3 anos. Clinicamente referia somente tonturas com movimentos rápidos da cabeça. 0 exame objetivo confirmou a diferença tensional nos membros superiores de $50 \mathrm{mmHg}$ para a sistólica e de $20 \mathrm{mmHg}$ para a diastólica, menor à direita, onde o pulso radial era menos intenso. Possuia já Doppler dos vasos do pescoço que mostrava nos vasos carotídeos direitos espessamento adiposo difuso concêntrico, fluxo com espetro do tipo "tardus parvus"e inversão do fluxo da artéria vertebral direita, sem outras alterações relevantes. A angio-TC toraco-abdominal era normal pelo que se realizou angio TC cervical que mostrou trombose do tronco arterial braquiocefálico, com permeabilização das artérias carótida, subclávia e vertebral direitas, com grande diminuição do calibre face às contra-laterais (Figuras 1 e 2). Conforme avaliação em consulta de cirurgia vascular, iniciou hipocoagulação e será considerada cirurgia se surgirem sintomas. Mantém-se assintomática, em vigilância clínica. Atendendo à idade da doente, tempo de evolução, aspeto de infiltração adiposa no eco-Doppler cervical, ausência de outros sintomas, sinais inflamatórios ou eventos trombóticos prévios concluimos que a oclusão será de causa aterosclerótica, afastando diagnósticos como arterite de Takayasu, displasia fibromuscular ou a existência de um estado pró-trombótico.

A oclusão aterosclerótica do tronco braquiocefálico corresponde a menos de $2 \%$ das causas extracranianas de insuficiência cerebrovascular, sendo suspeita quando a diferença tensional entre os membros superiores é superior ou igual a $15 \mathrm{mmHg}$. É muitas vezes assintomática, podendo tornar-se evidente tanto a nível da circulação cerebral pelo Síndrome de Sequestro Subclávio, Insuficiência da Circulação Vertebro-basilar ou Acidentes Vasculares Cerebrais Transitórios, como por sintomas isquémicos a nível do membro superior ${ }^{1}$. Internacionalmente é recomendada cirurgia de revascularização ou intervenção endovascular em doentes sintomáticos ou quando seja necessário utilizar a artéria mamária interna para revascularização coronária². Este caso mostra a evolução silenciosa da aterosclerose, mesmo quando envolve um território tão vasto e primordial como o da circulação cerebral, e como uma simples medição da tensão arterial pode revelar a oclusão de uma artéria importante.

\section{Bibliografia}

1. Kapa S, Adams J, Subclavian steal and rest pain in a case of brachiocephalic artery occlusion, Int J Angiol. 2008 Autumn; 17(3): 166-167.

2. Brott $\mathrm{T}$, Halperin $\mathrm{J}$ et all, Guideline on the Management of Patients with Extracranial Carotid and Vertebral Artery Disease, Circulation. 2011;124:e54-e130

\section{Diagnóstico: Oclusão assintomática do tronco braquiocefálico Magda Sousa, Jorge Henriques}

Serviço de Medicina Interna, Centro Hospitalar do Baixo Vouga - Aveiro. Portugal

Figura 1. Imagem de reconstrução digital de Angio-TC cervical mostrando a oclusão do tronco braquiocefálico (seta)

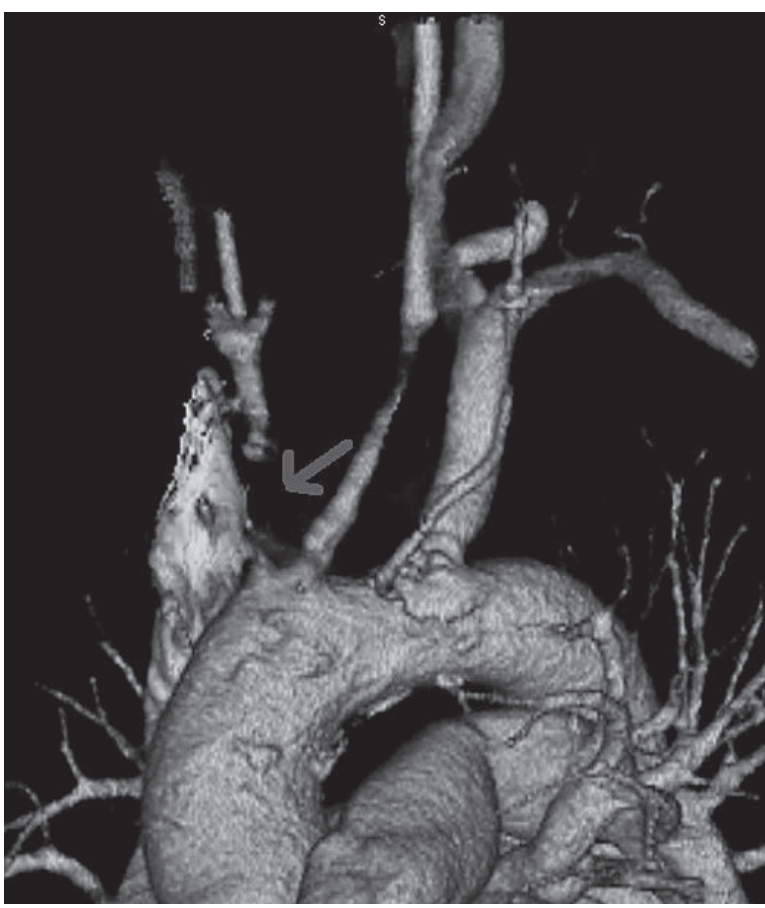

Figura 2. Corte sagital de Angio-TC cervical mostrando 0 tronco braquiocefálico $(A)$, não se verificando a passagem de contraste no mesmo - seta (B)

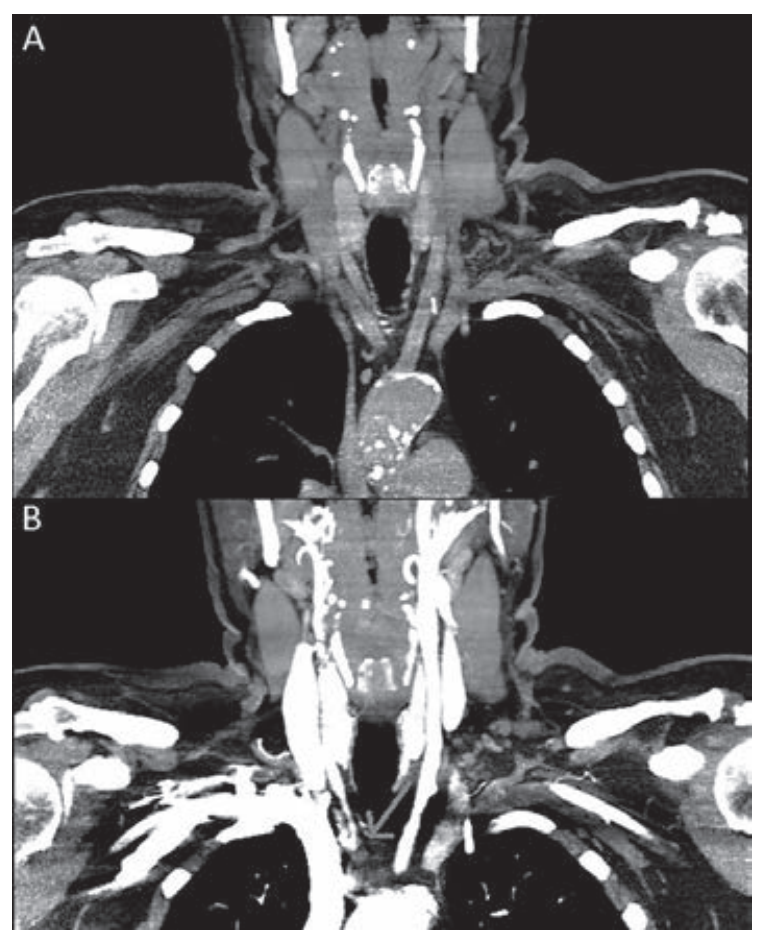

